\title{
Malin Alkestrand
}

\section{Walking in Someone Else's Shoes The Body Switch in the Engelsfors Trilogy}

\begin{abstract}
In the second book in the Swedish fantasy series about the town Engelsfors, Fire (2013), a dysfunctional group of witches is forced to unite and work together in order to hide that they have switched bodies with each other. This version of the body-switching motif is different from the more common body switch between two characters in that five people who are all focalised throughout the experience take part in it. The body switch is closely tied to a learning process about the need for cooperation and understanding for other people's life situations, which in turn emphasises the different girls' intersectional power positions (cf. Crenshaw "Demarginalizing the Intersection of Race and Sex"). Through the process of walking in someone else's shoes, the girls get to experience how it feels to watch their own body and life from a distance. Simultaneously, they get to play the part of someone else. As a consequence, they learn about both their own life situation and intersectional power position, and about the girl whose body they temporarily reside in. Thus, the literalisation of the figure of speech "to walk in someone else's shoes" becomes a learning process. By positioning each individual young woman as the active subject in another girl's life and the passive object in their own life, the body switch functions as a fantasy literary equivalent to the photograph motif, which according to Roberta Seelinger Trites often is deployed as a vehicle for illuminating how people are simultaneously the subject and the object in their own lives in realistic adolescent literature (123). The article is based on the concept of intersectionality, photograph theory, Mikhail Bakhtin's carnival theory, and Tzvetan Todorov's theory on how fantastic literature can turn figures of speech into literalised facts. These theories are all used to investigate how the body switch problematises and changes the witches' ability to influence their respective life situation.
\end{abstract}

Keywords: body switch, fantasy literature, learning process, intersectionality, carnival, Engelsfors trilogy, Sara Bergmark Elfgren, Mats Strandberg 


\section{Introduction}

The body switch is a common motif in contemporary popular culture, especially in fantasy fiction. Karin Nykvist investigates how Bella Swan, the protagonist in Stephenie Meyer's Twilight series (20052008), wants to replace her human body with a vampire body (31). This is just one example of how vampire novels explore the transformation from being a human to becoming a supernatural creature. Kimberley McMahon-Coleman discusses the Doppelgänger motif in the television show The Vampire Diaries (2009-2017) where several different characters have Doppelgängers (280-284). For example, the main character Elena Gilbert's Doppelgänger, Katherine Pierce, used to be both her current and previous boyfriend's lover, and she is now a vampire who repeatedly plays the role of Elena in order to take over her life. McMahon-Coleman argues that "it is difficult to see the Katherine/Elena doubling as anything other than a Madonna/ whore dichotomy" (284), which illustrates that Doppelgängers can be used to portray physically identical characters with opposing character traits. The Harry Potter series by J. K. Rowling (1997-2007) contains many examples of how characters disguise themselves as someone else with magic. For example, Hermione Granger uses Polyjuice Potion to look like Bellatrix Lestrange in Harry Potter and the Deathly Hallows (2007), which makes it possible for her, Harry Potter and Ron Weasley to get into the Ministry of Magic and find a magic object that has to be destroyed in order to defeat the evil wizard Lord Voldemort.

Lisa K. Perdigao analyses a body switch between the main character Buffy Summers and her antagonist Faith Lehane in the television series Buffy the Vampire Slayer (1997-2003) (15-19). Here, Faith decides to use a magic device in order to take over Buffy's life. For example, she has sex with Buffy's boyfriend and attempts to get Buffy imprisoned instead of her. Perdigao's analysis of Faith's failure to use the same language as Buffy clarifies how the inconsistency between body and mind is revealed for viewers in this particular body switch (15). Gaby Allrath argues that the body switch initiates a character development in Faith, as she decides to take on the responsibility of being a vampire slayer after some time of ignoring her quest, even though she risks being captured by Buffy and thereby ruin her plan to frame Buffy for one of her own crimes (139). Thus, this body switch is tied to identity development.

This brief overview illustrates that there are different versions of the body switch motif within the fantasy genre. In some cases the 
protagonist's life is invaded by an evil opponent, and in other cases it becomes a vehicle for the protagonist to get access to an antagonist's life and privileges. Usually characters transform into a different state of being, for example become a vampire, or switch bodies in pairs. In this article I explore the body switch in Fire (2013), the second book in the Engelsfors trilogy (originally published 2011-2013), a Swedish fantasy series written by Sara Bergmark Elfgren and Mats Strandberg. Here, five teenage witches in a witch circle switch bodies with each other.

My argument in this article is twofold. Firstly, I argue that the body switch in Fire represents a unique version of the body switch motif as it includes five characters who are all focalisers during the body switch, and the body switch is portrayed as a learning process that becomes central to the characters' identity development and ability to cooperate in the fight against evil. Through the experience of living a different girl's life for three days, they learn not only about the life, habits, and struggles of the person whose body they reside in, but also about their own strengths and weaknesses, and their privileges or lack thereof. More specifically, they come to realise that an individual's intersectional power position affects their life and gives them different opportunities to stake out their futures.

An intersectional approach to power highlights that it is impossible to separate one power category from another in people's lives; they interact with each other, and as a consequence they transform each other. For example, Kimberlé Crenshaw, who coined the term, has clarified how intersectionality can be applied to how black women are treated within American courts. Crenshaw argues that black women have been discriminated due to an intersection of racism and sexism, which leads to black women being treated differently than both black men and white women within the court system ("Demarginalizing the Intersection of Race and Sex"; "Mapping the Margins"). In my analysis of the body switch, intersections between class, parents' professions and age are especially relevant. ${ }^{1}$ In short, I will investigate how the characters' access to power is dependent on these intersections, and how living another girl's life highlights differences between the girls' respective intersectional power positions.

Secondly, I argue that the body switch is an example of how fantasy literature can turn figures of speech, such as "walking in someone else's shoes", into realised facts in order to communicate an ideological content in a genre specific way. I rely on Tzvetan Todorov's theory about how "fantastic literature" can turn metaphorical figures of 
speech into literal facts (79). There is a significant difference between Todorov's use of the term "the fantastic" and my understanding of the fantasy genre. Whereas the fantastic, according to Todorov, can be defined as literary fiction that makes readers wonder all the way throughout the narrative about whether the events that take place are supernatural or have a logical explanation, fantasy literature establishes the existence of the supernatural at an early stage (see Attebery 14-15). However, the same technique is used in the Engelsfors trilogy, which demonstrates that Todorov's definition is relevant for fantasy literature too. I will demonstrate how the literalisation of figures of speech through the body switch becomes a fantasy literary narrative technique which illuminates the importance of cooperation and empathy in Fire. ${ }^{2}$

\section{The Body Switch in Fire}

The setting of the Engelsfors trilogy is a fictional town in contemporary Sweden called Engelsfors. Seven adolescent witches, the Chosen Ones, are destined to save the world from an intrusion by demons. The Council, which is supposed to help the Chosen Ones hone their magic skills, controls the use of magic and has the power to enforce magic laws through severe physical punishments. It withholds information about the supernatural enemy, and this leads to the death of two of the witches. In Fire, the remaining members of the Circle switch bodies with each other through a magic ritual in order to save one of the girls, Anna-Karin Nieminen, from getting sentenced to death by the Council for abusing her magic (Fire 470-472). ${ }^{3}$ During the body switch they lose their magic skills and become ordinary girls (474-475). This is the purpose of the ritual, since their lack of magic powers makes it possible for them to lie in court without it being detected by a witch who has the ability to tell if witches are lying $(525,545-546)$. Since the focalisation varies between the five girls, all the girls' experiences of the event are depicted.

As mentioned earlier, the fact that there are five girls involved in the body switch makes it a particularly complex example of body switching. The girls have not switched bodies in pairs, with person A ending up in person B's body and vice versa. Instead, person A has jumped into person B's body, while person B has ended up in person C's body. The distinction between the girls' identities is constantly blurred when the characters literally get to walk in someone else's shoes. 


\section{Both Actor and Spectator: Investigating the Distinction between Subject and Object}

In Fire, the unity between a character's consciousness and their body dissolves as a consequence of the magic ritual that causes the body switch. The separation of a girl's body from her consciousness problematises the distinction between body and consciousness. Anthony Synnott investigates different conceptions of the relationship between body and soul during different time periods. He points out that René Descartes considers the thinking self to be the same as the soul, and that he sees the soul as completely separated from the body. More contemporary philosophers such as Jean-Paul Sartre erase the distinction between the concepts by arguing that the body is the self and that the self is the body. Hence, Sartre replaces the dualism with a monism. Still, contemporary theory on the relationship between body and soul remains heavily influenced by Descartes' dualism. Synnott underlines how the body has replaced the soul as the most highly regarded in the dichotomy. This understanding of the relationship between body and soul is significantly different to how Socrates regards the soul as trapped within a bodily prison, and how Aristotle argues that the soul cannot be free until the body dies. Both these thinkers regard the soul as superior to the body (Synnott 38, 41, 43). In the following section, I will discuss how the relationship between body and consciousness is portrayed via the body switch in Fire.

When the girls perform the magic ritual, they do not know what is going to happen, only that it will help them save Anna-Karin:

"Can we open our eyes now?" Vanessa [Dahl] hears herself say. But I didn't say that, she thinks. It was my voice. But I didn't do the speaking. She gradually opens her eyes and realises that she is looking at her own face. Vanessa is standing next to herself and holds her own hand. She lets it go. "What happened?" she says, quite shocked, and hears that her voice is not her own. (Fire 472)

Vanessa soon realises that her mind has been separated from her body. Someone else is suddenly in command of it, while her mind resides in another girl's body.

The body switch in Fire suggests that even though each girl's consciousness has been separated from its physical home, the body still holds some traces of its real owner during the body switch. For example, one of the girls experiences a craving for cigarettes, although she has never been addicted to smoking herself. The craving she feels belongs to the girl whose body she is temporarily inhabiting. Thus, 
in Fire a person's sense of self cannot be defined either by their body or their mind. Instead, the girls' identities are embodied, as traces of the person remain in the body after the mind has been transferred to a different girl's body. The remaining connection between the body and the mind challenges a dichotomous view of the relationship between body and mind. The two entities are depicted as interrelated and impossible to fully separate from each other. ${ }^{4}$ Hence, via the physical separation of body and consciousness, the interdependence of body and mind in defining a person's sense of self is underlined.

Due to fantasy literature's ability to literally separate the body from the mind, it raises existential questions concerning the distinction between body and mind, and the self and other people in a radical manner. This is underlined in the narrative, when figures of speech such as hearing yourself say something and standing beside yourself are turned into literal facts (cf. Todorov). For example, Vanessa does hear someone else use her voice; she actually stands beside herself and holds her own hand; she literally gets to walk in someone else's shoes (472-473). The confrontation with another person could hardly be portrayed in a more concrete and radical way. This body switch thus illustrates the relevance of applying Todorov's argument about how fantastic literature can turn figures of speech into realised facts to fantasy literature.

In Fire, there is even an explicit reference to turning metaphorical figures of speech into facts. Anna-Karin reflects on how it feels to reside in Ida's - her bully's - body: "Anna-Karin vaguely remembers that there's an old saying about how you learn to know your enemy by walking in his shoes. So far, it has been surprisingly satisfying to be in Ida's shoes. To be in her body, generally" (476). By foregrounding this figure of speech, the narrative underscores how the body switch can be interpreted as a staging of figurative speech through the genre characteristic of magic. Thus, the fantasy genre is employed to investigate experiences of taking on another person's perspective in a highly concrete way.

A recurring motif during the body switch is the gaze. The girls experience another girl's body and life from a subject position, at the same time as they have to stand aside and watch themselves as objects while another girl lives their life. Thus, they get to view both their body and their life from a distance. During the body switch the girls become the active subject in another person's life. However, they are no longer in control of their own bodies; the latter becomes an object they can only view from a distance. The girls try to describe their experiences: 
"It's so totally unreal. Like watching yourself in a movie" [Minoo Falk Karimi says]. "The most advanced 3D-film in the world, though. And then there's this thing about being audience and actor at the same time", Anna-Karin points out. Or, rather, Vanessa does. (492)

This simile illustrates how the girls are both the subject and the object in the movie of their life. Just like actresses who play the part of a character, the girls dress up in the other person's body, and perform their identities. The blurring of the line between the girls is underlined in the quote, where it becomes obvious that the person who is supposedly talking - Anna Karin - is in fact Vanessa, residing in Anna-Karin's body.

The body switch in the Engelsfors trilogy can be viewed as a fantasy literary counterpart to the photograph motif. In Disturbing the Universe, Roberta Seelinger Trites argues that the act of taking and watching photographs is a recurring motif in adolescent literature, which highlights how individuals simultaneously exist in the world as both subjects and objects. Through the photograph, the relationship between the acting subject and the object, which is being "acted upon", can be explored (123). While taking photographs is an active action, the photograph itself turns subjects into frozen objects without agency. In Trites' literary material, which consists mainly of realistic fiction, the young protagonists watch photographs, and hence get to experience themselves as both subjects and objects at the same time. The photograph points to the difficulty of establishing a distinction between the subject and the object position (124-125).

The crucial difference between the photograph motif and the body switch motif is that the relationship between subject and object is not investigated on a metaphorical level, but on a literal one. Vanessa acts as Anna-Karin, and views her own body from a distance with its new inhabitant, Linnéa Wallin. Vanessa's body, life situation and intersectional power position become objects, while she experiences Anna Karin's life from a subject position. Similar questions are raised as in Trites' examples of photographing protagonists, but they are posed in a more spectacular manner. The crossings of the line between subject and object are also more complex in the Engelsfors trilogy. The transgression of the boundaries between the girls is more definite, since they watch their bodies from a distance, while they experience someone else's body and life from a subject position. This raises the question Who am I? 
Another simile, which also conveys how the distinction between subject and object is challenged via the body switch, is utilised when Minoo hears someone else speaking with her voice: "'How can you be sure?' Minoo hears her own voice ask, but it sounds so different, like hearing your recorded voice" (Fire 474). Sound recordings display many similarities with photographs. They turn the voice of an active subject into a passive recording. Minoo's confusion stems from her no longer being the producer of the sound, but the one hearing it, and how this turns her own, familiar voice into something distant and foreign.

For the photographing characters that Trites analyse in her study, taking photographs helps them become empowered and active agents (124), but the body switch in Fire has both empowering and disempowering effects. The girls gain power over the person whose life they are forced to live, but they have to put the control of their own body and life in another girl's hands. Losing their magic powers affects all of their intersectional power positions profoundly. Instead of being the most powerful witches in the world, they return to their previous position as ordinary girls for as long as the body switch lasts. Thus, the hierarchy of power connected to being witches is turned upside-down. This displays similarities with Mikhail Bakhtin's understanding of the medieval carnival. Just like the king who had to play the part of the fool during the carnival (Bakhtin 81-82), the girls are temporarily removed from the pedestal of power that belongs to the Chosen Ones. Once again, they are ordinary girls, unable to protect themselves from the forces of evil. ${ }^{5}$

Both the photograph motif in Trites' examples and the body switch in Fire create situations in which the adolescents get an opportunity to experience themselves simultaneously as both subjects and objects. For the photographing characters in Trites' material, the photograph motif is closely intertwined with the adolescents' maturation: "[They] must perceive [themselves] clearly in order to achieve the emotional resolution that seems at times almost de rigueur in adolescent literature" (124). In Fire, the body switch has a similar function. It helps the girls consider their own lives, their intersectional power position, and their personalities in a way that initiates a process of maturation, in which they reflect on who they really are, and who they want to be. This, in turn, is a crucial step towards becoming adults. In the following sections, I will analyse how these insights are portrayed as a result of two intertwined processes: living another girl's life and watching someone else living your life. 


\section{Living Someone Else's Life}

In order for the girls' magic skills to be as powerful as possible, they have to learn to cooperate and combine their different types of powers, such as controlling minds and levitating objects. However, due to disputes between the girls, they have not been able to fully develop their magic skills. The body switch literally forces the girls to take on the perspective and intersectional power position of another Circle member. When they perform another person's life, they finally become a united group with common goals, since other people relate to them in a different way when they reside in another girl's body, which in turn deepens their understanding of the girl whose life they live during the body switch.

Minoo's experience of walking in Linnéa's shoes is portrayed as a realisation of how privileged she is. The girls' intersectional power positions are very different from each other. Minoo comes from a middle-class background, and she is a second generation Swede. She is also a high-achieving student, who is used to adults taking her perspective into consideration. Linnéa lost her mother at a young age, and her father is an alcoholic. She had to move from one foster family to another until the social services provided her with a flat of her own. Since Linnéa started abusing alcohol and drugs at an early age, the social services control her immensely; if she misbehaves, she will lose her flat and be put in a closed facility. From a financial standpoint, Linnéa has far less resources than Minoo's family, and she does not have parents who take an active part in her life. In short, Minoo is more privileged from a class perspective, and she also has the benefit of having parents who actively take part in her life, illustrating that the degree of control individuals of the same age have over their lives differs greatly due to how age intersects with other power categories, in this case predominantly class and social living conditions.

The most illuminating illustration of the difference between the two girls is Minoo's meeting at the social services office with Linnéa's contact person. When Minoo arrives in Linnéa's body, she realises that this is a part of reality she has never had to consider:

The social services department is just a block along from the Engelsfors Herald office [where Minoo's father works]. Minoo has probably passed by hundreds of times, but never actually noticed. The name in black lettering on the white background doesn't signify anything that matters in her life. (Fire 496) 
For Minoo, Linnéa's vulnerable position in society represents a part of reality which she has never had to deal with. Her first visit to the social services underscores the immense difference between the girls' intersectional power positions. Whereas Minoo does not have to worry about money or being put in a closed facility, Linnéa constantly struggles with limited financial resources and the risk of losing her flat and freedom.

The girls' differing family backgrounds do not only determine their class, but also the age-related restrictions they have to cope with. Minoo has a relatively big influence on her own life. For example, she has the possibility to decide if she wants to live with her mother or her father, when they take a break in their relationship (345-347). Linnéa is controlled to a much higher degree, which Minoo realises in an abrupt manner when the contact person at the social services decides that Linnéa will lose her flat and be put in a closed facility because they believe that she has disturbed her neighbours (498-499). Both girls are minors, but in Linnéa's case this means that she has little control over her own life. Here, an intersectional approach to power is necessary for the analysis, since the interaction between different power categories, specifically class and age, has direct consequences for the characters' power over their own lives.

For Minoo, the visit to the social services becomes a radical wakeup call about her own privileges. It is revealed that the contact person is controlled by magic, and that this is the reason why she wants to have Linnéa locked up (500). Symptomatically, it is Minoo, who is usually taken seriously by the adult world, who notices a locket hanging around the contact person's neck and tears it off. She is also able to convince the woman to let Linnéa keep her flat (499-502). Minoo realises how exposed Linnéa is, and she gains insight into the other girl's life, personality, and actions. The girls may be from the same town, but the body switch still leads to a cultural clash for Minoo. By experiencing Linnéa's life from a subject position, Minoo gets crucial information not only about Linnéa, but also about her own position in society. Thus, there is a different dimension to the experience of living someone else's life: the distancing effects that arise when the girls become separated from their own lives.

The body switch illustrates how being separated from your own life means losing control of it. For example, Linnéa, whose mind resides in Vanessa's body during the body switch, follows Minoo to the social services, but she has no control whatsoever over her own future. This is symbolised by the fact that she is not allowed to enter the room where the meeting is held (Fire 497). Linnéa has to put her 
own future in Minoo's hands and trust in her ability to keep Linnéa's life on track, while focusing on playing the part of Vanessa.

The contrast between the social services' control of Linnéa and Vanessa's mother's care for her daughter is illuminated during the body switch. While playing the part of Vanessa, Linnéa has to explain why she (that is, Vanessa) went to see a friend one night without telling her mother, and Linnéa does not know what to do. She has no previous experience of having a parent who cares about her actions, and her "immediate instinct is to be defensive. Let Jannike [Vanessa's mother] think what she likes" (484). However, she tries to put herself in Vanessa's position and she decides to admit it all and to apologise. As a consequence, she gets to experience something she has no memory of ever experiencing: Vanessa's mother tells her that she believes in her. Here, the differences between the girls' family situations are highlighted, and Linnéa gets to experience first-hand that parents can be supportive and caring.

The differences between the two girls' relationships to parents are reinforced when Vanessa's mother embraces Linnéa. This leads to conflicting emotions on Linnéa's behalf. She realises that this is something perfectly ordinary for Vanessa's body, “[b]ut to Linnéa, it was a reminder of what she has never experienced. And never will, ever" (484). The embrace activates a longing for a different life, but it also makes Linnéa realise that some parents are actually reliable and trusting. The effect is the same as in Minoo's case: the distancing effect that is created when the girls watch their own lives from afar. The girls' differences are not portrayed as an insurmountable obstacle when it comes to understanding and feeling empathy for other people. Instead, realising how their lives and intersectional power positions differ brings them closer together.

The body switch's similarities with Bakhtin's understanding of the medieval carnival are not limited to how the girls are dethroned from their position as the Chosen Ones during the body switch. Living another character's life also means that they temporarily take on a different intersectional power position. In some cases, such as Minoo's, the body switch strips a person of its privileges. In other cases, such as Linnéa's, the temporary power position is more privileged. Fire underlines how the way other people relate to individuals as a consequence of their intersectional power position can have an effect on both their personality and their self-image.

The body switch incorporates a subversive dimension for the characters. During the body switch, the girls get to experience a carnivalesque world that has been turned upside-down. When the girls 
return to their own bodies, they once again take on their usual power positions. At the same time, their magic skills and the power these skills give them are restored (503). However, they are no longer exactly the same people. Hence, in the same way as the flipping of the hierarchies during the medieval carnival became a way of displaying the artificiality and impermanence of the hierarchies of everyday life (Bakhtin 9-10, 81-82), the experience of playing the part of another Circle member demonstrates how each girl's respective intersectional power position is not a given, but is socially constructed. They can influence their selves, and as a consequence the body switch involves the possibility of development in terms of the girls' personalities.

\section{Watching Yourself from a Distance}

The experience of living another girl's life lets the girls perceive that other person's life from a subject position. The insights gained from watching your own life from a distance are a result of adapting an object position in your own life. This is similar to how Trites describes watching photographs of yourself as a distancing process (124-125). The body switch becomes an opportunity for the girls to re-evaluate their own sense of self, and to critically analyse their own behaviour. The separation of the body and the mind leads to confusing situations.

Mirrors repeatedly accentuate this confusion. For example, Minoo reflects on the relationship between her mind and Linnéa's body in front of a mirror:

Minoo has never believed that body and soul can be separated, not completely anyway. Now, she knows for certain. Linnéa's feelings for Vanessa are part of her whole body. [---] Her head spins and she has to look away from the mirror. Who is she actually seeing there and whose mind is producing these thoughts? Shouldn't she be able to access Linnéa's memories and emotions, now that she is thinking with Linnéa's brain? Or does her awareness of being Minoo in fact come from her own brain, but somehow projected into Linnéa's body? (Fire 485)

Minoo's questions are never answered, but the mirror scene highlights the clash between bodies and minds. In the mirror, she sees herself as someone else, and this is also what everyone else sees when they look at her, apart from the other girls who know the truth. Trapped in Linnéa's body she has to take a step back from herself, and adapt Linnéa's position. Just like the photograph, the mirror 
transforms us into objects, and this effect is further underlined when Minoo watches Linnéa's body in the mirror.

Another example where the mirror motif displays the inconsistency of body and mind is a scene where Vanessa looks at her own body being controlled by Linnéa: "Vanessa can't stop staring. It is like looking at yourself in the mirror but still not the same" (472). This underscores how her body becomes an object when someone else is in control of it. The transition from subject to object gives Vanessa a different vantage point, which in turn creates a new perspective where the distinction between herself and Linnéa is partly erased. In both of these examples, the mirror motif illuminates the importance of the gaze in the narrative. The girls look at the foreign body they reside in, their own bodies when they are controlled by another girl, and the rest of the girls whose bodies and minds do not match. This creates distorted and intricate perspectives, which change the way the girls view both themselves and others.

Jacques Lacan's conception of the mirror stage can give insights about these instances of the mirror motif. According to Lacan, an infant moves into the mirror stage when it first sees itself in a mirror, or sees itself reflected in its mother's eyes, and meets the other's gaze. Via the reflection, the infant sees itself as a unified subject for the first time. However, Lacan argues that what the infant perceives as a unified subject is actually a misunderstanding: the self is not united, but shattered (75-80). The mirror scenes that I have described illustrate the dissonance between consciousness and body during the body switch. In front of the mirror the illusion that Minoo is a coherent person is shattered: her body is not present and it is occupied by Ida. Minoo's body has temporarily merged with Ida, who represents the other. The gaze that Minoo faces is her own, but only to a limited degree, since the eyes she is looking into the mirror with are Linnea's, not her own. Thus, the mirror scenes help underline how the self is literally shattered during the body switch. Instead of giving the false illusion that the self is a coherent unit, these particular instances of the mirror motif illustrate what Lacan sees as the true, shattered self. Thus, they are the opposite of the mirror stage, but they still lead to insights about the relationship between the self and other people similar to the ones that Lacan connects to the mirror stage.

For Ida, the bully who lives in a rich and self-centred family, the body switch initiates a personality change. She begins to question the way she has treated other people and decides to become a more caring person. Whereas the three other girls have been focalisers since the beginning of the fantasy series, Ida and Linnéa do not become 
focalised until the second book. As a consequence, in the first book in the series, The Circle (2012), Ida is only portrayed via the other girls' critical opinions - as the cold-hearted bully.

However, in Fire Ida's most private thoughts and feelings are portrayed. While playing the part of Minoo, Ida talks to Gustaf Åhlander, who she has been in love with for years. Being disguised in Minoo's body gives Ida the opportunity to finally receive an honest and uncensored answer to why Gustaf does not like her, and she finds out that he thinks she is selfish, false, and emotionless (505-509). Ida tries to defend herself by explaining that she is trying to change her personality: "'I think Ida is... different now,' Ida says. 'She kind of grasps that she's been wrong. At times.' Gustaf looks searchingly at her. 'Like, I think she's trying to become a better person'" (508). This dialogue illustrates what happens when the girls play the part of someone else: Ida listens to a conversation in which the boy talks about her in the third person, as if she were not present. She also talks about herself in the third person, as if she were Minoo.

The conversation is portrayed as an epiphany for Ida. She decides that she no longer wants to be the person she used to be, and that she needs to make changes in order to become a person that Gustaf can learn to love (508-509). Ida's experiences show that the two results of the body switch-adopting another girl's perspective by taking on her subject position, and watching your own life from an object position-are intertwined. The interplay between these processes leads to Ida becoming a new person: "Even though Ida is Ida once more, she doesn't quite recognise herself. Something has changed in her. For the first time ever, she feels that she belongs with the Chosen Ones. Not that she is keen or anything. But she has accepted her fate" (554). Ida's evaluation of herself is depicted as a prerequisite for her future cooperation with the other Circle members. The girls' magic skills become stronger and easier to control after the body switch (618-620), a reward for the progress they have made in terms of cooperation.

The changes that Ida has gone through during the body switch distance her from the rest of her family. For example, Ida's family does not approve of her socialising with Linnéa, who they consider to be a drug addict, and who also has a much less privileged class position and less social status than Ida's wealthy family. As a consequence, they exclude Ida from social events and meals (573-577). The distance from Ida's previous life is underlined by the fact that she no longer knows what type of clothes she wants to wear: "It is as if she's inside an alien body once more. As if she's not the real Ida, but still has to keep up the pretence. She slides her finger across the 
pile of neatly folded tops, across the dresses on their hangers. Her stock of 'Ida' disguises" (573). Although Ida has returned to her own body, she still plays the part of someone else: the girl she used to be. Her clothes can be interpreted as representing her old bullying and unlovable self. Ida knows that she has to change, but she is not yet sure who she wants to become. The feeling of not being comfortable with her old clothes thus becomes a metaphor for her feelings of alienation from her family and the person she used to be.

Despite her family's behaviour, Ida succeeds in becoming a more humble and empathetic person. She has resisted her powers for a long time, not wanting to be a part of the Circle, but she is finally ready to embrace them: "Now, for the first time, she feels that her powers are part of her. And that she loves exerting them. She even loves the other Chosen Ones. A bit anyway. She must be on a magic high" (654). The acceptance of her magic abilities and their empowering effects are closely connected to the realisation that she has a lot in common with the other girls in the Circle.

Ida's last decision in life makes her a fantasy literary heroine. She unselfishly throws herself in front of Gustaf in order to save him from an evil witch, but the magic kills her (655-656, 663-664). Her development from a selfish, bullying girl to a young woman who is prepared to sacrifice herself for a person she loves is completed. When Ida dies her soul enters the spirit world, watching her own funeral, and she realises that the girls in the Circle were actually the ones who knew her best (686). Her identity development is thus portrayed as a result of the body switch and the interaction with the other members in the Circle. The implications of the body switch are explicitly stated by Anna-Karin: "'And maybe that was another reason for the body exchange' [...]. 'That we should get to know each other even better than before'" (550). The fulfilment of the quest relies on the girls' ability to cooperate. They have to confront their prejudices, and it is not until they have been forced to live someone else's life that the characters are able to approach each other with understanding and an open mind. The dysfunctional group has shown trust in each other and learnt how to cooperate.

At the very end of the trilogy, the Circle stands united for the first time ever despite the death of three of its members. The final defeat of evil takes place when Ida's soul and the souls of the rest of the dead members, who also ended up in limbo, take part in a magic ritual together with the members who are still alive (The Key 781-791). Thus, Ida gets the opportunity to recreate herself and contribute to the quest indiscriminately. She also tells Anna-Karin that she is sorry 
for the way she has treated her (797). Consequently, the existence between life and death can be seen as a purgatory for Ida, where she is cleansed of her sins.

For Ida, the body switch marks a transition from childhood to adulthood. As a result of her experiences of playing the part of someone else, and of distancing herself from her own life, she matures. The ability to understand other people's life situation and needs, and to put other people's needs before her own, is portrayed as a prerequisite for making the transition from child to adult. Thus, there are similarities between the Engelsfors trilogy and the Bildungsroman, where a young person develops, matures, and reaches adulthood (Trites 10-12). Sanna Lehtonen argues that in fantasy literature "girl characters' bodily transformations are crucial in relation to subjectivity because in their different forms the girls also have different experiences of embodiment, they are able to enter different gendered subject positions and their personal identity narrative is affected by the transformations" (13). The example of Ida clearly shows how the distancing perspective of the body switch contributes to the characters' learning process by positioning the girls in an object position in their own lives. Thus, bodily transformations influence their identity development.

\section{An Enchanted Learning Process}

The body switch motif in the Engelsfors trilogy functions as a narrative device that communicates an ideological content. By turning figures of speech into literalised facts, it raises questions regarding the interaction between different people, the importance of overcoming prejudices, and the need for cooperation in the fight for a better society, or world. By positioning the girls as the active subject in another girl's life and the passive object in their own life, the body switch functions as a fantasy literary equivalent to the photograph motif, which according to Trites often is deployed as a vehicle for illuminating how people are simultaneously the subject and the object in their own lives in realistic adolescent literature (123).

The body switch functions as a learning process for the characters in many different ways. Firstly, by living the life of someone else, they gain insight into both their own intersectional power position and the power position of the girl whose life they enact. They realise that class, upbringing, their parents' financial situation, and their parents' life choices have a major effect on their chances of making their own, independent decisions about their lives as minors. They 
also deepen their understanding of other people's actions as a consequence of having lived another girl's life. This, in turn, helps them to acknowledge their own prejudices and to adapt another girl's outlook on life, while simultaneously recognising the importance of trusting in each other in order to become a strong witch circle. The girls have to take on someone else's perspective, which in Ida's case initiates an identity development with the goal of becoming a more empathetic person.

The body switch is also closely connected to the quest. In order to succeed in the fight against evil the girls have to cooperate and unite their magic powers, and the body switch forces them to do so in a radical way. In fact, the support of the other members in the Circle becomes a substitute for adult helpers. The Circle has two adults assisting them, one male and one female, but in the end they are not nearly as important for the fulfilment of the quest as the cooperation with the other members of the Circle. Consequently, the body switch and the insights that follow are portrayed as necessary for the girls' transformation into fantasy literary heroines.

Biographical information: Malin Alkestrand holds a PhD in comparative literature from Lund University, Sweden. She is currently an assistant professor in comparative literature at Linnæus University in Sweden. Her doctoral thesis, Magiska möjligheter: Harry Potter, Artemis Fowl och Cirkeln i skolans värdegrundsarbete (Magical Possibilities: Teaching Values in Schools with Harry Potter, Artemis Fowl and The Circle) (2016), explores how fantasy literature for young readers, for example the Harry Potter series, can be used in schools when discussing democracy, human rights, and multiculturalism. In the article "Righteous Rebellion in Fantasy and Science Fiction for Young Readers", included in Hype: Bestsellers and Literary Culture (2014), she analyses a youth rebellion in the Harry Potter series.

\section{Works cited}

Alkestrand, Malin. Magiska möjligheter: Harry Potter, Artemis Fowl och Cirkeln i skolans värdegrundsarbete. Makadam, 2016.

Allrath, Gaby. "Life in Doppelgangland: Innovative Character Conception and Alternate Worlds in Buffy the Vampire Slayer and Angel". Narrative Strategies in Television Series, edited by Gaby Allrath \& Marion Gymnich, Palgrave Macmillan, 2005, pp. 132-150. 
Attebery, Brian. Strategies of Fantasy. Indiana University Press, 1992.

Bakhtin, Mikhail. Rabelais and His World. Translated by Helen Iswolsky, The M. I. T. Press, 1968.

Crenshaw, Kimberlé. "Demarginalizing the Intersection of Race and Sex: A Black Feminist Critique of Antidiscrimination Doctrine, Feminist Theory and Antiracist Politics". The University of Chicago Legal Forum, vol. 40, 1989, pp. 139-67.

---. "Mapping the Margins: Intersectionality, Identity Politics, and Violence against Women of Color". Stanford Law Review, vol. 43, no. 6, 1991, pp. 1241-299.

Davis, Kathy. "Intersectionality as Buzzword". Feminist Theory, vol. 9, no. 1, 2008, pp. 67-85.

Elfgren, Sara B. \& Strandberg, Mats. Fire. Translated by Anna Paterson, Hammer, 2013.

---. The Circle. Translated by Per Carlsson, Hammer, 2012.

---. The Key. Translated by Anna Paterson, Hammer, 2015.

Hancock, Ange-Marie. “When Multiplication Doesn't Equal Quick Addition: Examining Intersectionality as a Research Paradigm". Perspectives on Politics, vol. 5, no. 1, 2007, pp. 63-79.

Lacan, Jaques. Ecrits: The First Complete Edition in English. Translated by Bruce Fink in collaboration with Héloïse Fink \& Russell Grigg, W. W. Norton \& Company, 2006.

Lehtonen, Sanna. Girls Transforming: Invisibility and Age-Shifting in Children's Fantasy Fiction since the 1970s. McFarland \& Company, 2013.

Long, Douglas C. "The Bodies of Persons". Journal of Philosophy, vol. 71, no. 10, 1974, pp. 291-301.

Lykke, Nina. "Nya perspektiv på intersektionalitet: Problem och möjligheter". Kvinnovetenskaplig tidskrift, no. 2-3, 2005, pp. 7-17.

McMahon-Coleman, Kimberley. "Myriad Mirrors: Doppelgangers and Doubling in The Vampire Diaries". Open Graves, Open Minds: Representations of Vampires and the Undead from the Enlightenment to the Present Day, edited by Sam George \& Bill Hughes, Manchester University Press, 2013, pp. 210-224, ro.uow.edu.au/asdpapers/441. Accessed Sept 2017. 
Nykvist, Karin. "The Body Project". Interdisciplinary Approaches to Twilight, edited by Mariah Larsson \& Ann Steiner, Nordic Academic Press, 2011, pp. 29-45.

Perdigao, Lisa K. "'I Hear It's Best to Play Along': The Poststructuralist Turn in Buffy the Vampire Slayer". Slayage, vol. 8, no. 4, 2011, pp. $1-16$.

Rowling, J. K. Harry Potter and the Deathly Hallows. Bloomsbury, 2007.

Synnott, Anthony. "Body: Tomb, Temple, Machine, and Self". 1993. Sociology of the Body: A Reader, edited by Claudia Malacrida \& Jacqueline Low, Oxford University Press, 2008, pp. 7-37.

Todorov, Tzvetan. The Fantastic: A Structural Approach to a Literary Genre. Translated by Richard Howard, Cornell University Press, 1975.

Trites, Roberta Seelinger. Disturbing the Universe: Power and Repression in Adolescent Literature. University of Iowa Press, 2000.

Valentine, Gill. "Theorizing and Researching Intersectionality: A Challenge for Feminist Geography". The Professional Geographer, vol. 59, no.1, 2007, pp. 10-21.

\section{Notes}

1 For some other examples of studies from an intersectional perspective, see Lykke; Davis; Hancock; Valentine.

2 The article expands my analysis of the body switch, which is included in the chapter "Kulturmöten" ("Multiculturalism") in my doctoral thesis Magiska möjligheter: Harry Potter, Artemis Fowl och Cirkeln i skolans värdegrundsarbete, pp. 237-285, where I explore the didactic potential of the body switch regarding discussions about multiculturalism in schools. I relate the ideologies concerning multiculturalism connected to the body switch to the Swedish school curriculum for elementary school and upper secondary school.

3 I refer to the titles of the books in the Engelsfors trilogy throughout the article in order to make the in-text citations efficient.

4 For an analysis of how the body switch motif and its possible real-life equivalents relate to the philosophical discussion of the concepts of body and mind, see Douglas C. Long's "The Bodies of Persons".

5 In "Mänskliga rättigheter" ("Human Rights") in Magiska möjligheter, pp. 171-235, I discuss how Anna-Karin's abuse of her magic powers in order to transform herself from being bullied to becoming the most popular student in school can be interpreted as a carnival, similar to the medieval carnival described by Bakhtin. 